\title{
Resistor-less Single-purpose or Reconfigurable Biquads Utilizing Single Z-Copy Controlled-Gain Voltage Differencing Current Conveyor
}

JEŘÁBEK, J.; ŠOTNER, R.; POLÁK, J.; LANGHAMMER, L.; HERENCSÁR, N.; PROKOP, R.; VRBA, K.

Journal of Circuits Systems and Computers

2017, vol. 26, iss. 3, pp. 1-21

ISSN (Print): 0218-1266

ISSN (Online): 1793-6454

DOI: http://dx.doi.org/10.1142/S0218126617500505

Accepted manuscript

Electronic version of an article published as Journal of Circuits Systems and Computers 2017, vol. 26, iss. 3, pp. 1-21, DOI 10.1142/10.1142/S0218126617500505 (C) 2017 World Scientific Publishing Company, http://www.worldscientific.com/worldscinet/jcsc 


\title{
RESISTOR-LESS SINGLE-PURPOSE OR RECONFIGURABLE BIQUADS UTILIZING SINGLE Z-COPY CONTROLLED-GAIN VOLTAGE DIFFERENCING CURRENT CONVEYOR
}

\author{
JAN JERABEK*, ROMAN SOTNER, JOSEF POLAK, LUKAS LANGHAMMER, NORBERT \\ HERENCSAR, ROMAN PROKOP, KAMIL VRBA \\ Faculty of Electrical Engineering and Communication, Brno University of Technology, Technicka 12, \\ Brno, 616 00, Czech Republic \\ jerabekj@feec.vutbr.cz \\ sotner@feec.vutbr.cz \\ xpolak24@phd.feec.vutbr.cz \\ langhammer@phd.feec.vutbr.cz \\ herencsn@feec.vutbr.cz. \\ prokop@feec.vutbr.cz. \\ vrbak@feec.vutbr.cz \\ Received (Day Month Year) \\ Revised (Day Month Year) \\ Accepted (Day Month Year)
}

\begin{abstract}
Presented work deals with applications of the single Z-Copy Controlled-Gain Voltage Differencing Current Conveyor (ZC-CG-VDCC) in single purpose and multifunctional biquadratic voltage- and current-mode active resistor-less filters. Electronically adjustable features of the active device (intrinsic current input resistance $R_{\mathrm{x}}$, current gain $B$ and transconductance $g_{\mathrm{m}}$ ) are controlled by DC bias current. These mentioned adjustable features allow interesting possibilities of control of the pole frequency and quality factor. Four voltage-mode solutions realizing low-pass, band-pass, high-pass and band-reject filtering solutions were designed together with two current-mode filters. The current-mode solutions have curious multifunctional capability based on full utilization of electronically controllable parameters of the ZC-CG-VDCC. Two adjustable parameters of the ZCCG-VDCC (intrinsic current input resistance and transconductance) are used for electronic setting of features of the filter (pole frequency, quality factor, tuning). Control of the third adjustable parameter (current gain) causes reconnection-less change of the transfer function between iAP (inverting all-pass response) and $\mathrm{iBR}$ (inverting band-reject responses). Simulation results in PSPICE and Cadence CDS 6 are used to show characteristics of the proposed circuits.
\end{abstract}

Keywords: Biquads; current gain; electronic control; intrinsic resistance; reconnection-less multifunctional filter; transconductance; z-copy; ZC-CG-VDCC.

\section{Introduction}

Biquadratic active filters are very typical applications in analog signal processing [1]. Many approaches and solutions are known in literature, for instance [2, 3]. It is not possible to discuss all known solution in this contribution, therefore important examples were selected for further explanation.

\footnotetext{
${ }^{*}$ Corresponding author.
} 
The most requested solutions are so-called multifunctional biquads [4] based on Kerwin, Huelsman and Newcomb (KHN) types [5]. These filtering structures provide many transfer functions simultaneously (low-pass - LP, band-pass - BP, high-pass - HP, band reject - BR and all-pass - AP). Basic and very favorable solutions are utilizing operational transconductance amplifiers (OTAs) in several variants [6]. Many various solutions based on OTAs were described and discussed in literature (for example [7-9]). Multifunctionality and various possibilities of electronic control of application usually require high number of these simple active devices in filtering application. On the other hand, very simple solutions utilizing only non-controllable current- or voltage-followers are also available (examples are in [10-12], also in frame of current conveyors [13]. However, electronically controllable features of the application are usually very restricted.

Another approaches to the synthesis consider combination of several different types of active elements in filtering application [14].

Similarly, advanced types of current conveyor (CC) [15] have controllable parameter known as intrinsic current input resistance $\left(R_{\mathrm{x}}\right)$ [16] that is also very useful in control of active filters [17]. They found employment in active devices, which combines several sub-blocks in internal topology. Typical example is so-called current differencing transconductance amplifier (CDTA) $[4,18]$ where current differencing unit and OTA are combined together $[18,19]$. Similar approach was used in construction of so-called current conveyor transconductance amplifier (CCTA) [20] and [21] for example or current follower transconductance amplifier (CFTA) [22]. Mentioned active elements allow to combine both above discussed types of electronic control $\left(g_{\mathrm{m}}, R_{\mathrm{x}}\right)$ in frame of one active device that improves possibilities of direct electronic control in applications. CDTA has modification, known as modified current differencing transconductance amplifier (MCDTA) [23]. Its parameters, input resistance, $z$ terminal resistance and transconductance are electrically reconfigurable. Current-mode active elements with controllable current gain $(B)$ were introduced in $[24,25]$. Therefore, it is possible to find also active devices where various combinations of parameters $\left(g_{\mathrm{m}}, R_{\mathrm{x}}, B\right)$ are independently and electronically adjustable. For example Minaei et al. [26] and Kumngern et al. [27] showed implementation of $R_{\mathrm{x}}$ and $B$ control and Marcellis et al. [28] utilized adjustable current gain and voltage gain control in frame of active device [29].

Resistor-less filters have typical feature - no external resistors are required for their operation. OTAs allow such design [7-9] but some features are not available because OTA has only one electronically controllable parameter (transconductance $-g_{\mathrm{m}}$ ). The latest literature [30-32] shows that resistor-less filtering applications are very popular. Some from latest works dealing with single active element based filters do not allow any possibility of electronic control [33], require external resistors [33, 34] or proper outputs of the responses are not available [33]. In addition, change of the input or output node (terminal) for change of the transfer function is required in these solutions.

Filtering applications, proposed in this contribution, use active device, that combines three types $\left(g_{\mathrm{m}}, R_{\mathrm{x}}, B\right)$ of electronically and independently controllable parameters and 
therefore allows multiple control of application. This active device was derived from basic variant of the voltage differencing current conveyor (VDCC) [4] and is called zcopy controlled-gain voltage differencing current conveyor (ZC-CG-VDCC). Behavioral model is shown in Fig. 1. This paper is focused on electronically controllable resistor-less biquadratic ( $2^{\text {nd }}$ order) single ZC-CG-VDCC-based filters and shows how to construct voltage-mode solutions providing all basic $2^{\text {nd }}$ order filtering functions with ZC-CGVDCC and two current-mode filters where one type has very unusual, interesting and useful controllable feature (allows reconnection-less change of type of the transfer function).

Controllable features, that ZC-CG-VDCC offers, are not common in previous works. One known solution was published in [35], where the same type of reconnection-less change of the transfer function is available. Unfortunately, the quality factor of the circuit in [35] was restricted to 0.5 . In comparison to [35], this solution allows to obtain higher quality factor, theoretically limited only by available range of $g_{\mathrm{m}}$ and $R_{\mathrm{x}}$ control.

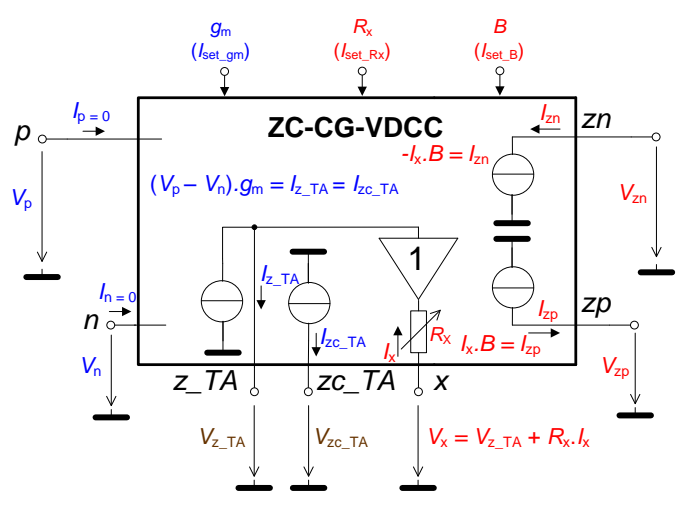

Fig. 1 Behavioral model of the z-copy controlled-gain voltage differencing current conveyor (ZC-CG-VDCC)

The parameters of the active elements in Fig. $1\left(g_{\mathrm{m}}, R_{\mathrm{x}}, B\right)$ are controlled by DC bias currents. Voltage difference $\left(V_{\mathrm{p}}-V_{\mathrm{n}}\right)$ at high-impedance input terminals is transformed to current $I_{Z_{-} \text {TA }}$ through $g_{\mathrm{m}}$ of the OTA subsection. Identical copy of the $I_{Z_{-} \text {TA }}$ is available at the high-impedance terminal $z c_{-} T A$. Voltage $V_{\mathrm{X}}$ (low-impedance current input terminal $\mathrm{X})$ is given by $R_{\mathrm{X}}$ (intrinsic resistance) and $V_{\mathrm{z}_{-} \mathrm{TA}}$. Current through $\mathrm{X}$ terminal, $I_{\mathrm{X}}=\left(V_{\mathrm{X}^{-}}\right.$ $\left.V_{z_{-} \mathrm{TA}}\right) / R_{\mathrm{x}}$, is available at high-impedance current output terminals $z_{\mathrm{p}}, z_{\mathrm{n}}$ (positive and negative) in amplified (by adjustable gain $B$ ) form. Detailed information are in [36].

\section{Proposed Filtering Applications}

The ZC-CG-VDCC elements can be easily applied in various filtering applications based on many standard synthesis and design approaches [4, 5, 7-9]. Even single ZC-CGVDCC is suitable for synthesis and construction of biquadratic voltage- and current-mode filters with some partial benefits. Absence of external resistors is typical feature of 
proposed structures. Following text discuss several single purpose (one transfer function) and multifunctional filtering applications and their possibilities. Finally, one of presented variants has reconnection-less and electronically reconfigurable properties that is very beneficial and useful.

\subsection{Voltage-mode low-pass filter}

The circuit in Fig. 2 has one grounded and one floating capacitor. Transfer function of the circuit has form:

$$
K_{V}(s)=\frac{\frac{B g_{m}}{C_{1} C_{2} R_{x}}}{s^{2}+\frac{B}{C_{1} R_{x}} s+\frac{B g_{m}}{C_{1} C_{2} R_{x}}},
$$

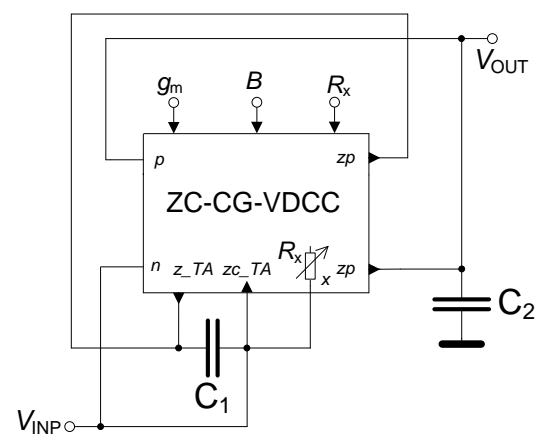

Fig. 2 Voltage-mode low-pass structure using ZC-CG-VDCC and two capacitors (one of them floating) where pole frequency and quality factor are given as:

$$
\omega_{p}=\sqrt{\frac{g_{m} B}{C_{1} C_{2} R_{x}}}, Q_{p}=\sqrt{\frac{g_{m} R_{x} C_{1}}{B C_{2}}} .
$$

Interesting feature of this configuration (for $B=1$ ) is that it allows control of pole frequency by $g_{\mathrm{m}}$ and $R_{\mathrm{x}}$ simultaneously whereas their product $g_{\mathrm{m}} \cdot R_{\mathrm{x}}$ designates quality factor of the filter (their ratio has to be kept constant while the pole frequency is tuned).

\subsection{Voltage-mode band-pass filter}

The band-pass filter in Fig. 3 has both capacitors grounded, that is significant advantage for IC design. Transfer function has very similar form as (1):

$$
K_{V}(s)=\frac{\frac{B}{C_{1} R_{x}} s}{s^{2}+\frac{B}{C_{2} R_{x}} s+\frac{B g_{m}}{C_{1} C_{2} R_{x}}},
$$


where pole frequency has the same form as (2) and quality factor is:

$$
Q_{p}=\sqrt{\frac{g_{m} R_{x} C_{2}}{B C_{1}}}
$$

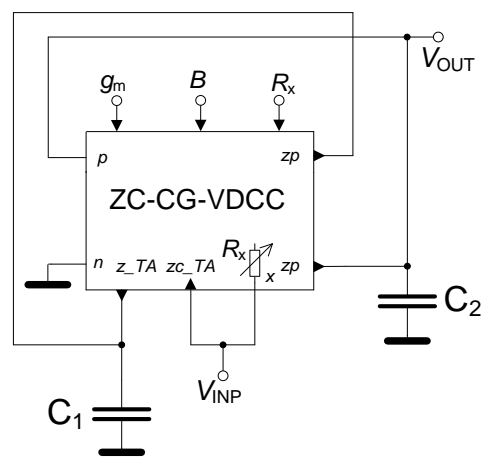

Fig. 3 Voltage-mode band-pass structure using ZC-CG-VDCC and two capacitors (both grounded)

\subsection{Voltage-mode high-pass filter}

The second-order high-pass filtering response is provided by structure shown in Fig. 4.

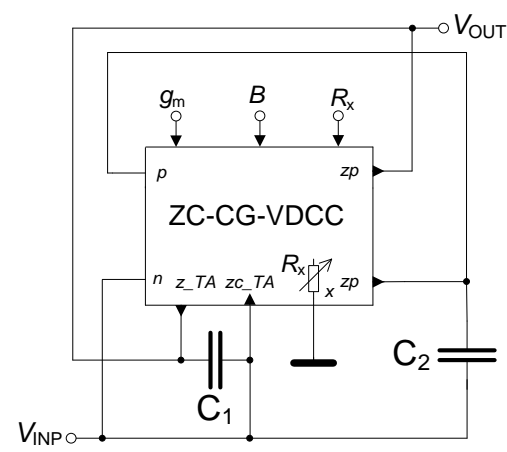

Fig. 4 Voltage-mode high-pass structure using ZC-CG-VDCC and two capacitors (both floating) Transfer function of the filter is as follows:

$$
K_{V}(s)=\frac{s^{2}}{s^{2}+\frac{B}{C_{1} R_{x}} s+\frac{B g_{m}}{C_{1} C_{2} R_{x}}},
$$

and its pole (quality factor) is the same as (2) and (3).

\subsection{Voltage-mode band-reject filter}

The structure in Fig. 5 provides band-reject response as is obvious from the equation: 


$$
K_{V}(s)=\frac{s^{2}+\frac{B\left(C_{1}-C_{2}\right)}{C_{1} C_{2} R_{x}} s+\frac{B g_{m}}{C_{1} C_{2} R_{x}}}{s^{2}+\frac{B}{C_{1} R_{x}} s+\frac{B g_{m}}{C_{1} C_{2} R_{x}}}
$$

Filter has band-reject characteristic if equality of both capacitor $\left(C_{1}=C_{2}\right)$ is ensured. Practically, structure in Fig. 5 is identical to Fig. 4, only output node is different. Pole frequency and quality factor are also identical to (2) and (3).

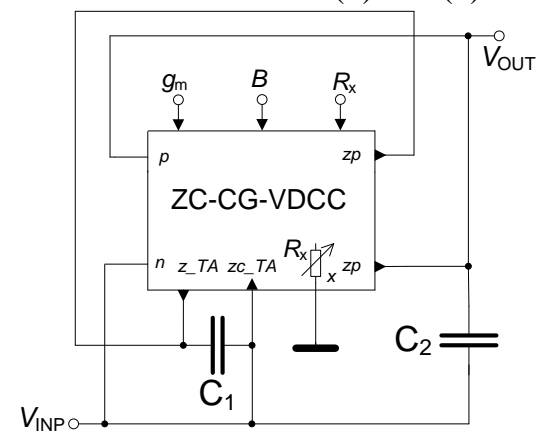

Fig. 5 Voltage-mode band-reject structure using ZC-CG-VDCC and two capacitors (both floating)

\subsection{Current-mode band-pass filter}

Band-pass filters are very important in many various applications in communication systems in both voltage- and current-mode. Therefore, we proposed also current-mode solution employing single ZC-CG-VDCC (Fig. 6).

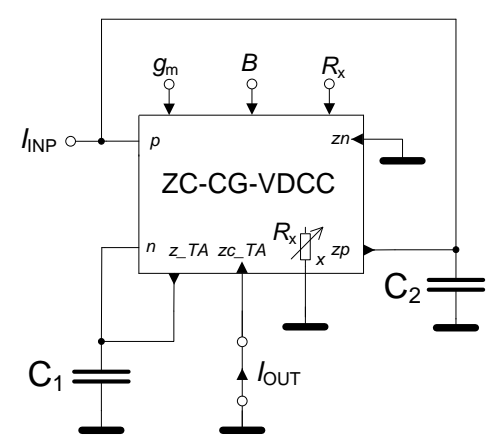

Fig. 6 Current-mode band-pass structure using ZC-CG-VDCC and two capacitors (both grounded)

Transfer function of the circuit has form:

$$
K_{I}(s)=\frac{\frac{g_{m}}{C_{2}} s}{s^{2}+\frac{g_{m}}{C_{1}} s+\frac{g_{m}}{C_{1} C_{2} R_{x}}},
$$


where pole frequency and quality factor are:

$$
\omega_{p}=\sqrt{\frac{g_{m}}{C_{1} C_{2} R_{x}}}, Q_{p}=\sqrt{\frac{C_{1}}{g_{m} R_{x} C_{2}}} .
$$

\subsection{Current-mode inverting all-pass and band-reject filter}

Very interesting solution of the multifunctional structure is shown in Fig. 7. The filter has reconnection-less reconfigurable character, that is not typical feature in known solutions. All controllable features of the ZC-CG-VDCC are fully utilized to control parameters of the filtering structure.

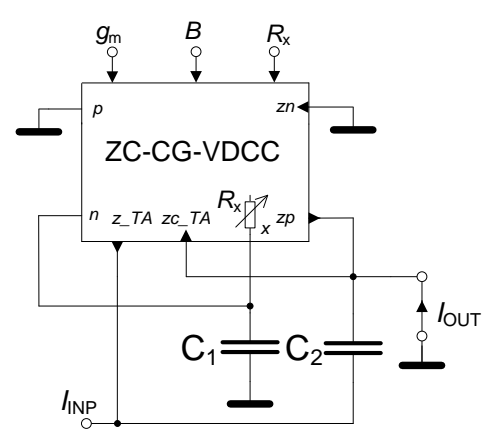

Fig. 7 Current-mode all-pass and band-reject electronically reconfigurable reconnection-less structure using ZC-CG-VDCC and two capacitors (one floating)

Transfer function can be found as very beneficial for controllable filters:

$$
K_{I}(s)=-\frac{s^{2}+\frac{\left(C_{2}-C_{1} B\right)}{C_{1} C_{2} R_{x}} s+\frac{g_{m}}{C_{1} C_{2} R_{x}}}{s^{2}+\frac{1}{C_{1} R_{x}} s+\frac{g_{m}}{C_{1} C_{2} R_{x}}},
$$

where inverting all-pass response is available for $B=2$ (if $C_{1}=C_{2}$ ) and inverting bandreject solution for $B=1$. Pole frequency has the same form as (9) but the quality factor is different:

$$
Q_{p}=\sqrt{g_{m} R_{x} \frac{C_{1}}{C_{2}}} .
$$

This transfer function allows change of the filter response between two types of transfer (iAP and iBR). The third function of the structure allows direct inverting transfer (iDT) between input and output for $B=0$ that can be useful in some cases at IC, where any other type of reconfigurability (reconnection of input, output, ...) without electronic control is problematic. 


\section{Verification of Theoretical Presumptions - Simulation results}

We selected solution in Fig. 7 for detailed analysis and simulation in Cadence OrCAD (PSpice) with CMOS model of the ZC-CG-VDCC presented in [36] in detail. We suppose equality of $C_{1}=C_{2}=C=100 \mathrm{pF}$ for easy application of the transfer type control by parameter $B$. Both electronically controllable parameters $g_{\mathrm{m}}$ and $R_{\mathrm{x}}$ are calculated from (9) and (12) as follows:

$$
g_{m}=\omega_{p} Q_{p} C, R_{x}=\frac{Q_{p}^{2}}{g_{m}} .
$$

Resulting parameters can be found as $g_{\mathrm{m}}=1.88 \mathrm{mS}$ and $R_{\mathrm{x}}=4.77 \mathrm{k} \Omega$ for pole frequency $f_{\mathrm{p}}=1 \mathrm{MHz}$ and quality factor $Q_{\mathrm{p}}=3$. DC bias control currents of the CMOS structure [36] are set to $I_{\text {set_gm }}=145 \mu \mathrm{A}$ and $I_{\text {set_Rx }}=4.9 \mu \mathrm{A}$. Results of the simulation for $B=1$ and $B=2$ are in Fig. 8. The complex space plot of polynomial numerator and denominator roots (zeros and poles) is depicted in Fig. 9. Obtained $f_{\mathrm{p}}$ was $993 \mathrm{kHz}$. Supply voltage was $V_{\mathrm{DD}}=V_{\mathrm{SS}}= \pm 1 \mathrm{~V}$ and power consumption is below $7.4 \mathrm{~mW}$.

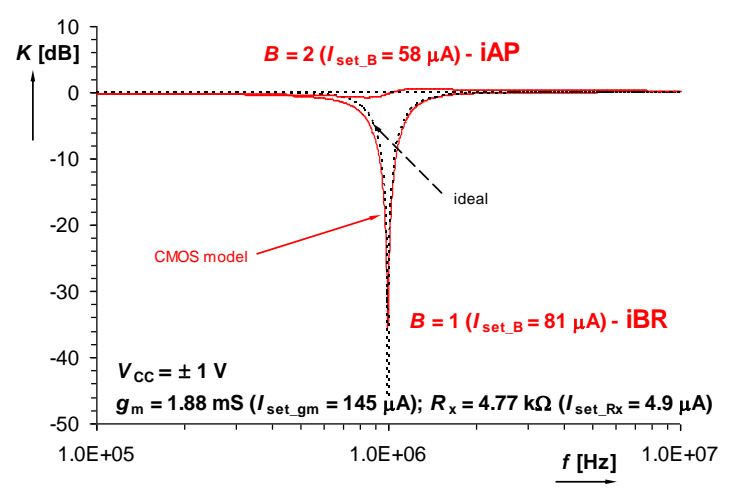

Fig. 8 Magnitude responses of the filter for two values of current gain $B$ (electronic change of the transfer type between iBR and iAP response)

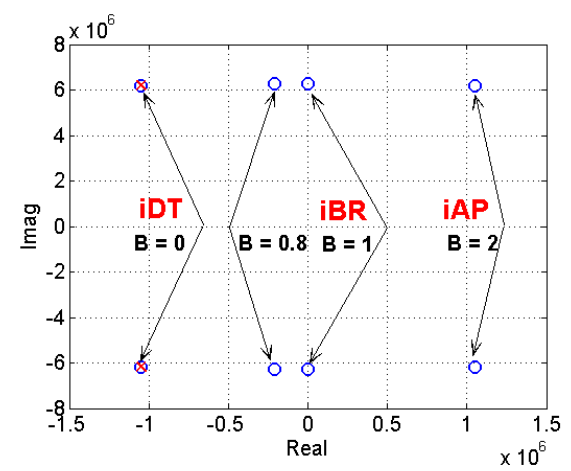

Fig. 9 Complex space plot of the zeros migration of the filter 
Change of the stop-band gain (attenuation) is possible by $B$ in range $\langle 0 ; 1\rangle$ as Fig. 10 shows (tested $B$ values are $0.5,0.8$ and 1). Phase responses are documented in Fig. 11.

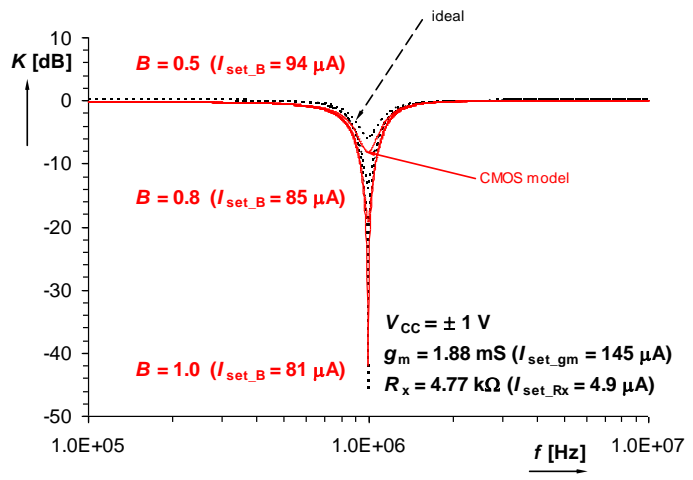

Fig. 10 Magnitude responses of the iBR filter for $B$ between 0.5 and 1

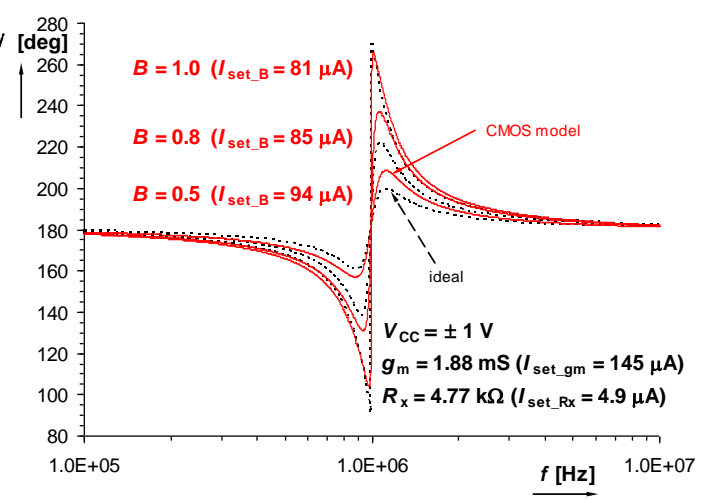

Fig. 11 Phase responses of the iBR filter for $B$ between 0.5 and 1

Maximal theoretical attenuation (minimal gain) at the pole frequency $\left(f_{\mathrm{p}}, \omega_{\mathrm{p}}\right)$ is given by:

$$
\left|K_{\min }\left(\omega_{p}\right)\right|=\frac{C_{2}-C_{1} B}{C_{2}},
$$

where, supposing $C_{1}=C_{2}=C$, we can found simplified form: $\left|K_{\min }\right|=1-B$. In logarithmic range:

$$
K_{\text {min }}[d B]=20 \log _{10}(1-B) .
$$

Resulting magnitude responses for higher gains $(B=1.5,1.8,2$ and 3$)$ are shown in Fig. 12. 


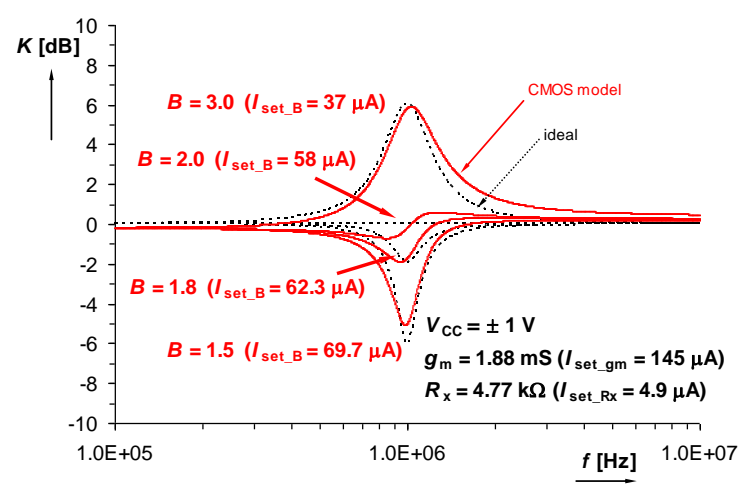

Fig. 12 Magnitude response of the filter for $B$ between 1.5 and 3

Table 1 Ideal and simulated results (Pole Frequency Tuning)

\begin{tabular}{|c|c|c|c|c|c|c|}
\hline $\begin{array}{c}g_{\mathrm{m}} \\
{[\mathrm{mS}]} \\
I_{\text {set_gm }} \\
{[\mu \mathrm{A}]}\end{array}$ & $\begin{array}{c}f_{\mathrm{p}} \\
\text { ideal } \\
{[\mathrm{kHz}]}\end{array}$ & $\begin{array}{c}f_{\mathrm{p}} \\
\text { simulated } \\
{[\mathrm{kHz}]}\end{array}$ & $\begin{array}{c}B W \\
\text { ideal } \\
{[\mathrm{kHz}]}\end{array}$ & $\begin{array}{c}B W \\
\text { simulated } \\
{[\mathrm{kHz}]}\end{array}$ & $\begin{array}{c}Q_{\mathrm{p}} \\
\text { ideal } \\
{[-]}\end{array}$ & $\begin{array}{c}Q_{\mathrm{p}} \\
\text { simulated } \\
{[-]}\end{array}$ \\
\hline $\begin{array}{l}0.15 \\
(5.5) \\
\end{array}$ & 282 & 278 & \multirow{5}{*}{335} & 335 & 0.84 & 0.83 \\
\hline $\begin{array}{l}0.25 \\
(9.9) \\
\end{array}$ & 364 & 363 & & 338 & 1.09 & 1.07 \\
\hline $\begin{array}{r}0.5 \\
(22) \\
\end{array}$ & 515 & 511 & & 345 & 1.54 & 1.48 \\
\hline $\begin{array}{r}1.0 \\
(54) \\
\end{array}$ & 729 & 724 & & 360 & 2.18 & 2.01 \\
\hline $\begin{array}{r}1.88 \\
(145) \\
\end{array}$ & 1000 & 993 & & 385 & 2.99 & 2.58 \\
\hline
\end{tabular}

Configurations of the iBR filter for two values of quality factor $Q_{\mathrm{p}}(0.74$ and 2.58) were tested and results are shown in Fig. 13. Simultaneous reconfiguration of $g_{\mathrm{m}}$ and $R_{\mathrm{x}}$ is required but electronic change of both parameters is very simple. 


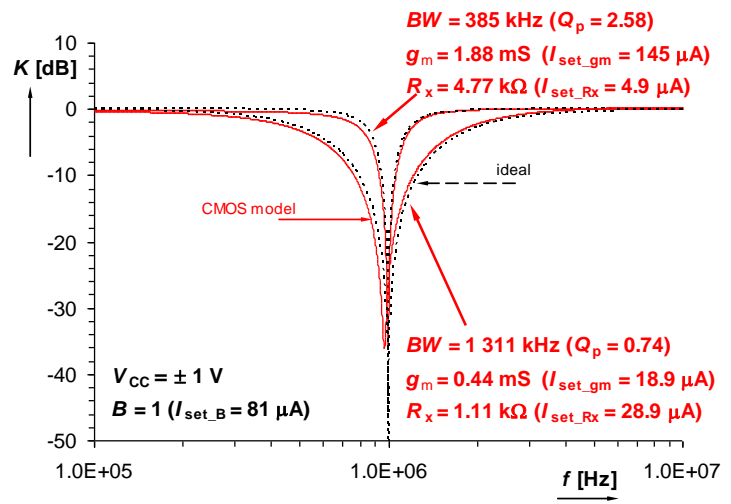

Fig. 13 Magnitude response of the iBR filter for two different values of $Q_{\mathrm{p}}$ at $f_{\mathrm{p}}=1 \mathrm{MHz}$

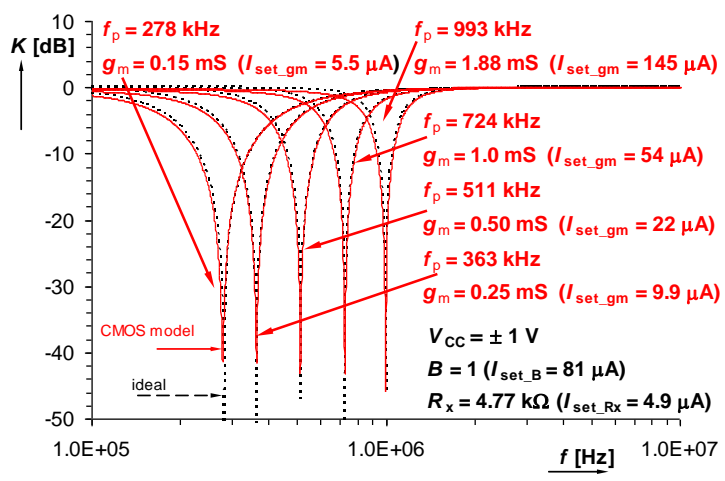

Fig. 14 Tuning of the iBR response with constant $B W$

Tuning of the iBR response is shown in Fig. 14 for adjusting of $g_{\mathrm{m}}$ in range from 0.15 to $1.88 \mathrm{mS}\left(I_{\text {set_gm }}=5.5-145 \mu \mathrm{A}\right)$. Adjusting of $g_{\mathrm{m}}$ only ensures $f_{\mathrm{p}}$ tuning without change of the bandwidth $(B W)$ theoretically, see Table 1 .

Configuration of the iAP filter $(B=2)$ was studied while $f_{\mathrm{p}}$ was tuned $\left(g_{\mathrm{m}}\right.$ values: $0.15,0.25,0.5,1.0,1.88 \mathrm{mS}$, the same values as in Tab. 1 ) and constant $Q_{\mathrm{p}}=2.58$ (as in previous case for iBR). Results are shown in Fig. 15 and Fig. 16 (magnitude and phase responses). The pole frequencies obtained in simulation results are very close to results in Tab. 1. Details are given in both figures (Fig. 15, Fig. 16). 


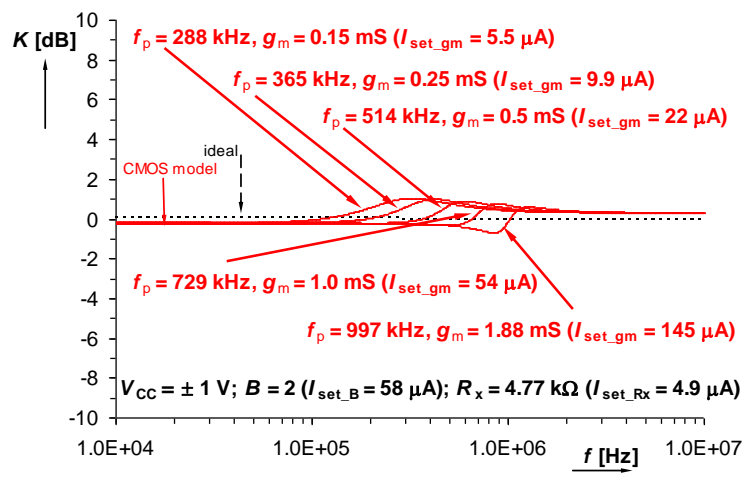

Fig. 15 Tuning of the iAP filter (magnitude responses)

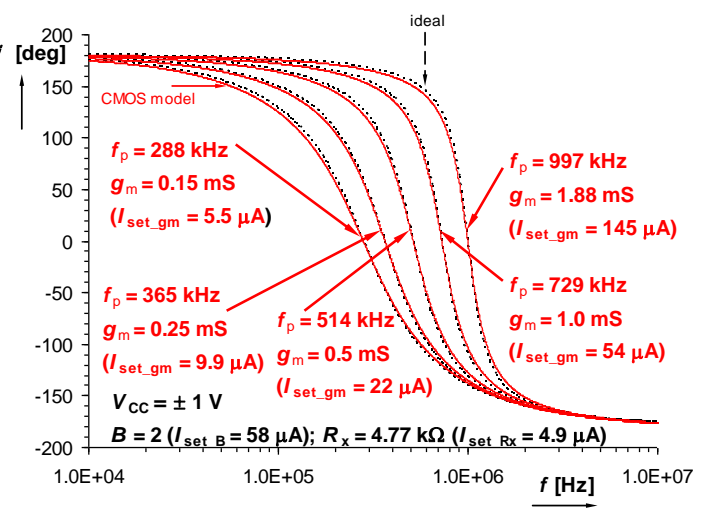

Fig. 16 Tuning of the iAP filter (phase responses)

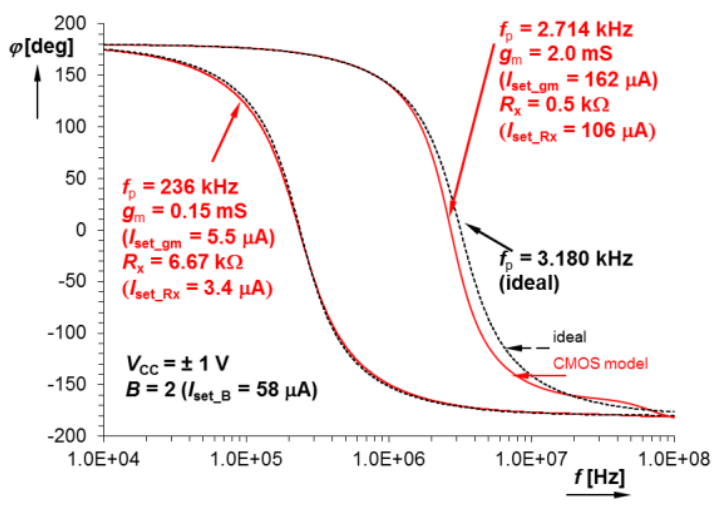

Fig. 17 Wide-range tuning of the iAP filter (phase responses) for two discrete values of $g_{\mathrm{m}}=R_{\mathrm{x}}$ 
The iAP response allows wide range of $f_{\mathrm{p}}$ when $Q_{\mathrm{p}}=1$ (when $g_{\mathrm{m}}=R_{\mathrm{x}}$ ). Range of $f_{\mathrm{p}}$ adjusting was verified from $236 \mathrm{kHz}$ to $2.714 \mathrm{MHz}\left(g_{\mathrm{m}}=0.15\right.$ and $\left.2 \mathrm{mS}\right)$, as is obvious from Fig. 17.

Monte Carlo and corner (incl. temperature effects) analyses in Cadence Virtuoso CDS 6 have been provided to see performance of the above discussed system (Fig. 7) in real conditions and under fabrication dispersion. Temperature was swept from -20 to $80 \mathrm{deg}$. of $\mathrm{C}$ for all corner runs. Monte Carlo (for 200 runs) and Corner analysis results are presented for $Q=0.7$ and $Q=2.58$ (all parameters in accordance to Fig. 13). An example of results for BR and setting $\mathrm{Q}=2.58$ is shown in Fig. 18 (Monte Carlo analysis) and Fig. 19 (corners and temperature effects). Corner analysis supposes about 60 possible combinations of temperature $(-20,0,20,80 \mathrm{deg}$.), four corner models for CMOS transistors and three models for capacitors.

Table 2 Process variation for AP configuration of the filter in Fig. 7

\begin{tabular}{|c|c|c|c|c|}
\hline & Monte Carlo & Corner (Worst Case) \\
\hline & mean & std. dev. & min. & max. \\
\hline \multicolumn{5}{|c|}{$Q=0.7$ (setting) } \\
\hline$f_{\mathrm{p}}[\mathrm{kHz}]$ & 1053 & 19.8 & 799 & 1428 \\
\hline$\Delta K[\mathrm{~dB}]^{*}$ & 1.55 & 0.25 & 1.34 & 2.83 \\
\hline \multicolumn{5}{|c|}{$Q=2.58$ (setting) } \\
\hline$f_{\mathrm{p}}[\mathrm{kHz}]$ & 1033 & 22.9 & 766 & 1429 \\
\hline$\Delta K[\mathrm{~dB}]^{*}$ & 1.30 & 0.29 & 0.94 & 2.78 \\
\hline
\end{tabular}

Table 3 Process variation for BR configuration of the filter in Fig. 7

\begin{tabular}{|c|c|c|c|c|}
\hline & \multicolumn{2}{|c|}{ Monte Carlo } & Corner (Worst Case) \\
\hline & mean & std. dev. & min. & max. \\
\hline \multicolumn{5}{|c|}{$Q=0.7$ (setting) } \\
\hline$f_{\mathrm{p}}[\mathrm{kHz}]$ & 1041 & 21.2 & 751 & 1412 \\
\hline$K_{\min }[\mathrm{dB}]$ & -24 & 4.7 & -55 & -4 \\
\hline$Q[-]$ & 0.67 & 0.01 & 0.66 & 1.20 \\
\hline \multicolumn{5}{|c|}{$Q=2.58$ (setting) } \\
\hline$f_{\mathrm{p}}[\mathrm{kHz}]$ & 1031 & 23.1 & 760 & 1424 \\
\hline$K_{\min }[\mathrm{dB}]$ & -35 & 7.9 & -48 & -5 \\
\hline$Q[-]$ & 2.55 & 0.04 & 2.51 & 3.90 \\
\hline \multicolumn{5}{|c|}{$* \Delta K-$ max. magnitude change from 0 dB at AP response }
\end{tabular}

$* \Delta K-$ max. magnitude change from $0 \mathrm{~dB}$ at AP response

The worst case (corner) analysis results indicate significant effect on $f_{\mathrm{p}}$ accuracy, and stop-band attenuation (BR response). It is quite typical behavior for presented range of temperatures. However, corner analysis really offers the most pessimistic scenario that will be most likely far away from real situation. Moreover, any influence on stop-band 
and $f_{\mathrm{p}}$ setting can be easily corrected by electronically adjustable parameters of the ZCCG-VDCC $\left(g_{\mathrm{m}}, R_{\mathrm{x}}, B\right)$ and therefore it is not so questionable.
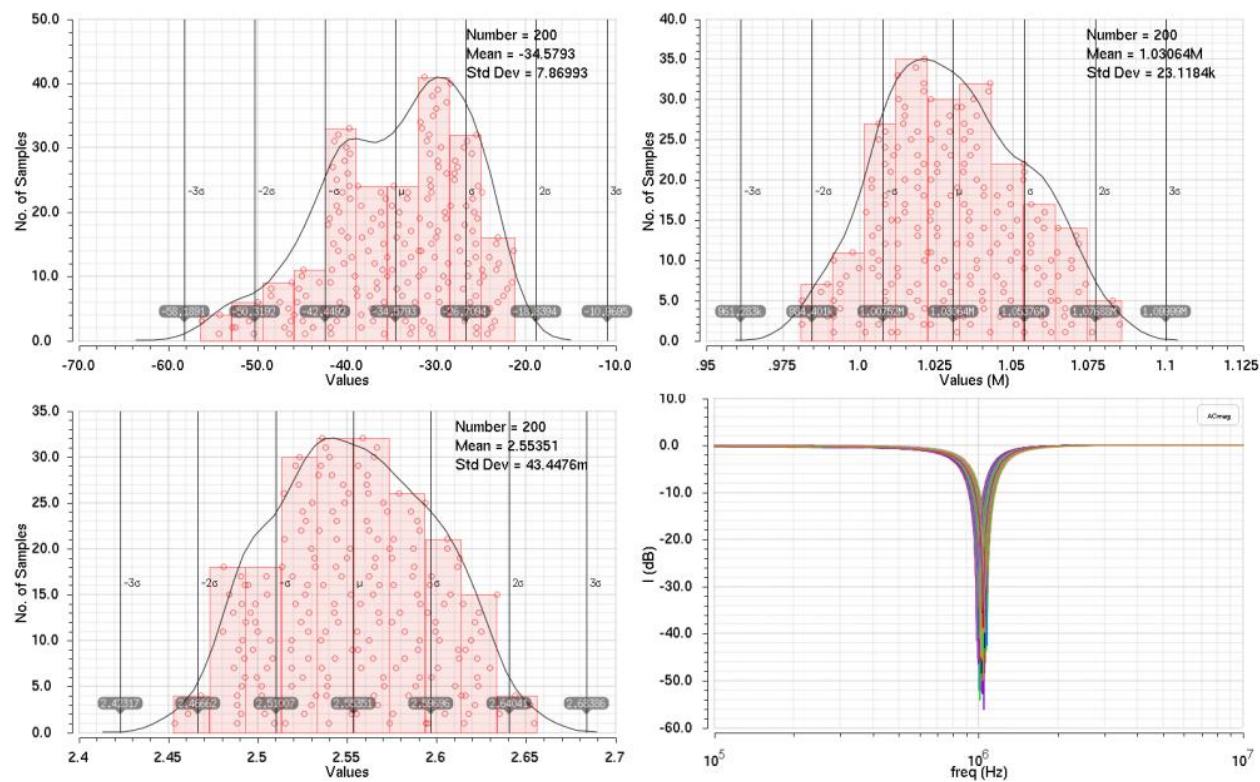

Fig. 18 Cadence Virtuoso CDS 6 Monte Carlo analysis results in case of BR response (from left side -
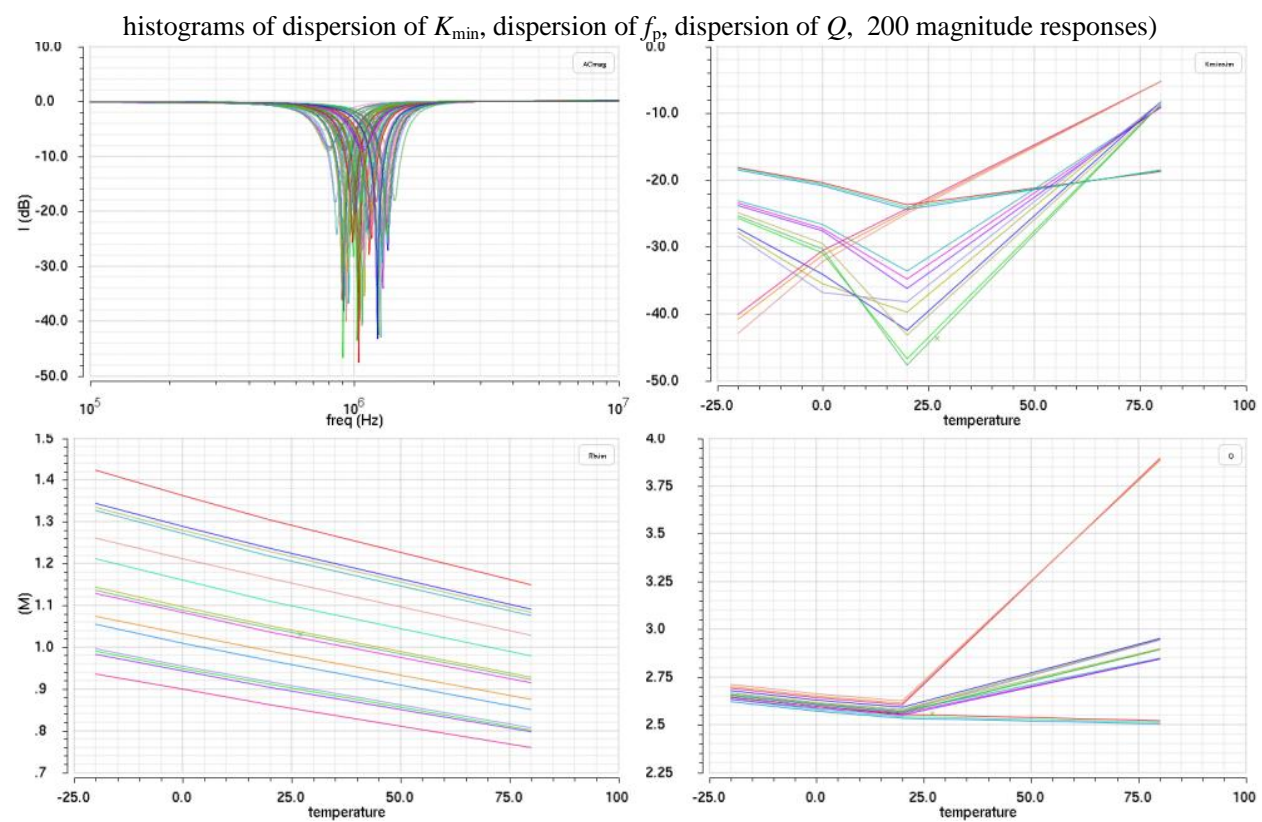

Fig. 19 Cadence Virtuoso CDS 6 Corner analysis results for BR response (from left side - magnitude responses for about 60 runs/combinations, dependence of $K_{\min }$ on corner groups and temperature, dep. of $f_{\mathrm{p}}$ on corner groups and temperature, dep. of $Q$ on corner groups and temperature) 


\section{Proposed Solutions Versus State-of-the-art}

ZC-CG-VDCC device has been utilized in structures regarding first-order filtering applications, see [36], [37]. Implementation of this device in second-order structures was not solved in the past.

In this work, ZC-CG-VDCC device was used in exemplary single-purpose second-order filtering structures that are available in frame of just one active device. To the best of author's knowledge no similar study, where ZC-CG-VDCC device has been used in design of second-order single purpose filters, is available in open literature. Therefore we prepared several voltage-mode and current-mode second-order filtering topologies (Fig. 2 - Fig. 6). Solutions serving for similar purposes based on another active devices (in many cases more than one) than ZC-CG-VDCC allow to establish similar transfer responses and can be found in open literature. We noted them in this paper only for completion of synthesis of second-order single purpose filters.

However, the structure in Fig. 7 belongs to reconfigurable second-order reconnection-less solutions that were also reported in literature several-times and significantly improve some features of reported circuits (complexity especially). First of all, to the best of author's knowledge, Fig. 7 is the first reported solution allowing electronic reconfiguration of the transfer function in frame of the single active devicebased biquad filter. Therefore, it is worth to provide precise comparison with recent knowledge and this structure was also analyzed in detail by simulations. Comparison of previously reported solutions of the second-order reconfigurable filters is provided in Tab. 4. Presented solution in Fig. 7 does not fulfill conditions for full universality (as we can see from the table it provides reconfiguration between three transfer functions), therefore there is still space for further improvements as we expect from our future work.

Table. 4 Comparison of previously reported reconnection-less reconfigurable filtering structures and solution

\begin{tabular}{|c|c|c|c|c|c|c|}
\hline 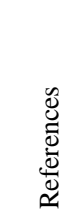 & 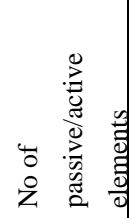 & 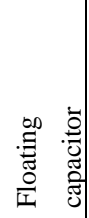 & 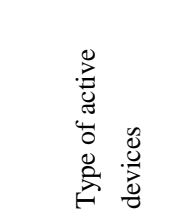 & 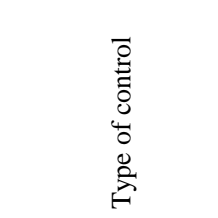 & 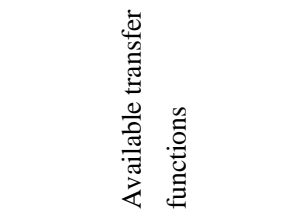 & 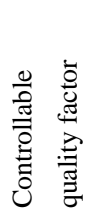 \\
\hline$[35]$ & $4 / 2$ & Yes & CCII & current gain & $\mathrm{AP}, \mathrm{BR}$ & No \\
\hline [38] & $7(4) / 7(6)$ & No & $\begin{array}{c}\text { CCII, CA, VB, } \\
\text { CF, OTA }\end{array}$ & $\begin{array}{c}\text { current gain } \\
\text { transconductance }\end{array}$ & $\mathrm{AP}, \mathrm{BR}$ & Yes \\
\hline [39] & $2-3 / 4$ & Yes & OTA & transconductance & AP, BR, HP, LPZ, HPZ & Yes \\
\hline [40] & $2 / 4$ & Yes & OTA & transconductance & $\begin{array}{c}\mathrm{AP}, \mathrm{BR}, \mathrm{HP}, \mathrm{BP}, \mathrm{LPZ}, \\
\text { HPZ }\end{array}$ & Yes \\
\hline Fig. 7 & $2 / 1$ & Yes & ZC-CG-VDCC & $\begin{array}{l}\text { transconductance, } \\
\text { current gain }\end{array}$ & $\mathrm{AP}, \mathrm{BR}, \mathrm{DT}$ & Yes \\
\hline
\end{tabular}


There are some solutions [39], [40] allowing reconnection-less reconfigurability between various transfer types (band-pass, low-pass and high-pass with transfer zeros) as well as control of quality factor as solution presented in this paper. However, they require higher amount of active devices (see Tab.4). In the class of the circuits providing reconfiguration between $\mathrm{AP}$ and $\mathrm{BR}$ response only, solution in [35] does not allow to control quality factor which is very low (0.5). Structure in [38], providing the same transfer responses, requires high number of passive and active elements. Therefore, circuit presented here overcomes several drawbacks of structures reported in previous works. Moreover, better controllability of reconfiguration of transfer function by current gain $(B)$ than by transconductance $\left(g_{\mathrm{m}}\right)$ is expected due to simpler availability of zero value of $B$ than zero value of $g_{\mathrm{m}}$ used in [39]-[40]. Solutions in [39] and [40] allows reconfigurability between higher number of transfer responses but number of required active devices is quite high and some transfer responses are not pure (BP with finite attenuation in the stop band for example).

In general point of view, single active device-based biquadratic structures reported in recent literature does not allow electronic reconfiguration between several transfer types as we can see from Tab. 5. There are drawbacks of many solutions regarding only limited and passive control (by $R$ or $C$ ) of specific features [3], [33], [34], [41]-[44]. Therefore, electronic controllability of some solutions is very restricted or not allowed. The second problem is requirement of many passive elements, see for example [3], [41], [43]. Only solutions in [21] and [23] are offering the same or even better features than circuits in Fig. 2 - Fig. 6 but these does not allow direct transfer and reconnection-less electronical reconfiguration between several transfer functions as circuit in Fig. 7. So the main features and differences of the transfer type change approach of the circuit in Fig. 7 among others are evident, see Tab. 5.

Tab. 5 General comparison of previously reported examples of single active device-based biquad filters

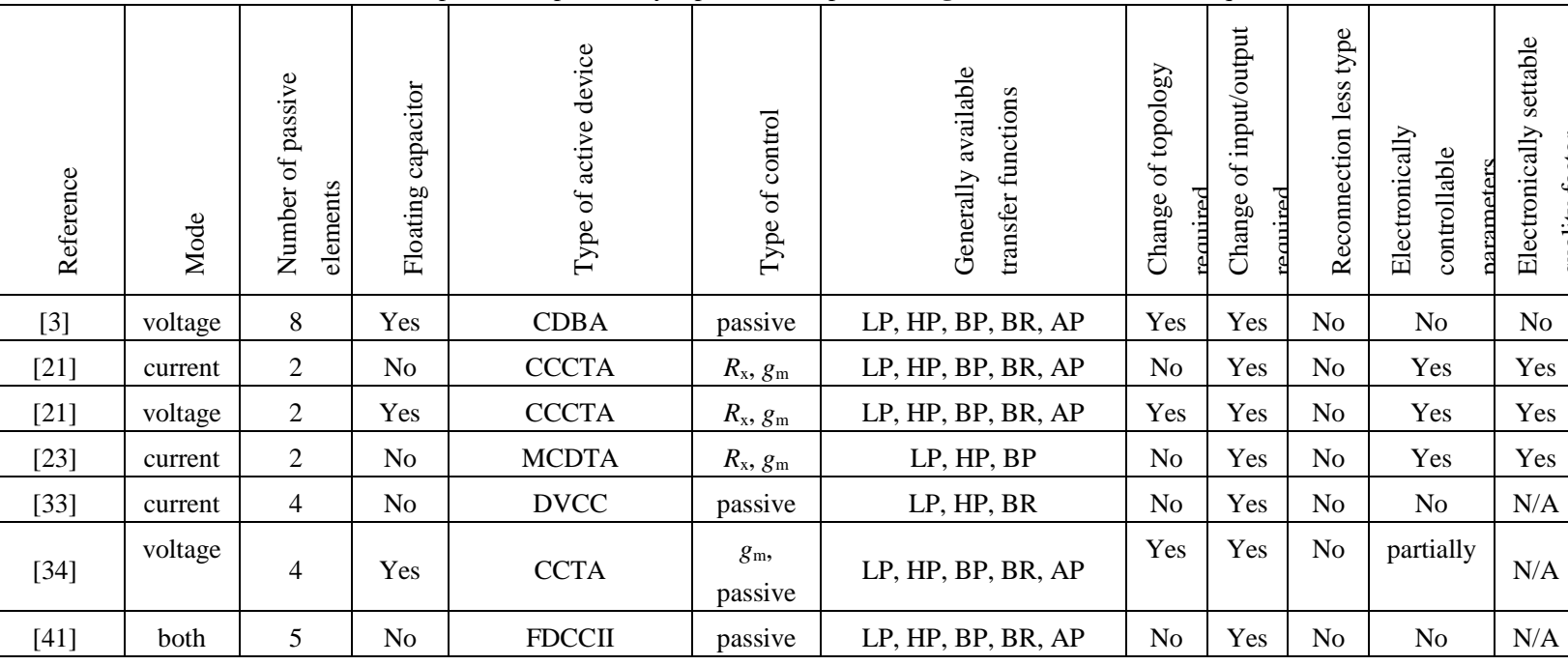




\begin{tabular}{|c|c|c|c|c|c|c|c|c|c|c|c|}
\hline [42] & current & 4 & No & FDCCII & passive & LP, HP, BP, BR, AP & No & Yes & No & No & N/A \\
\hline [43] & current & 5 & Yes & CFOA & passive & LP, HP, BP, BR, AP & Yes & Yes & No & No & N/A \\
\hline [44] & current & 4 & No & CBTA & $\begin{array}{c}g_{\mathrm{m}}, \\
\text { passive }\end{array}$ & $\mathrm{LP}, \mathrm{HP}, \mathrm{BP}, \mathrm{BR}, \mathrm{AP}$ & No & Yes & No & No & N/A \\
\hline [44] & voltage & 4 & No & CBTA & $\begin{array}{c}g_{\mathrm{m}}, \\
\text { passive }\end{array}$ & $\mathrm{LP}, \mathrm{HP}, \mathrm{BP}, \mathrm{BR}, \mathrm{AP}$ & No & Yes & No & No & N/A \\
\hline $\begin{array}{c}\text { Fig. } 2- \\
\text { Fig. } 5\end{array}$ & voltage & 2 & Yes & ZC-CG-VDCC & $\begin{array}{c}R_{\mathrm{x}}, g_{\mathrm{m}}, \\
B\end{array}$ & $\mathrm{HP}, \mathrm{BP}, \mathrm{BR}$ & Yes & Yes & No & Yes & Yes \\
\hline Fig. 7 & current & 2 & Yes & ZC-CG-VDCC & $\begin{array}{c}R_{\mathrm{x}}, g_{\mathrm{m}}, \\
B\end{array}$ & AP, BR, DT & No & No & Yes & Yes & Yes \\
\hline
\end{tabular}

Notes:

$\mathrm{CA}$ - current amplifier, $\mathrm{CF}$ - current follower, $\mathrm{CCII}$ - current conveyor of second generation, $\mathrm{CDBA}$ - current differencing buffered amplifier, CCCTA, current controlled current conveyor transconductance amplifier, MCDTA - multiple output current differencing transconductance amplifier, DVCC - differential voltage current conveyor, FDCCII - fully differential current conveyor of second generation, CFOA - current feedback, CBTA - current backward transconductance amplifier, OTA - operational transconductance amplifier, ZC-CGVDCC - z-copy controlled gain voltage differencing current conveyor, VB- voltage buffer

\section{Conclusion}

We introduced several interesting solutions of the biquad filters in voltage- and current-mode based on new single active device so-called Z-Copy Controlled-Gain Voltage Differencing Current Conveyor (ZC-CG-VDCC). All solutions utilize external capacitors only (resistor-less) and electronically controllable parameters for configuration of the filter characteristics. Circuits in Fig. 2 (LP), Fig. 3 (BP) and Fig. 4 (HP) have different topologies. Figure 5 (BR) has the same topology as Fig. 4, but other output response is presented. Denominators of transfer functions of solutions from Fig. 2 - Fig. 5 are identical. Current-mode representation of the band -pass filter is shown in Fig. 6. Both grounded capacitors are an advantage of this circuit. Solution from Fig. 7 presents very useful features. This circuit is very favorable for its electronically reconfigurable features (in IC design especially). Electronically adjustable parameters of the ZC-CGVDCC element are fully employed for electronic change of the transfer function (inverting all-pass and band-pass response) without reconnection of nodes (input/output) and electronic control of parameters of the filter. The last noted filter was selected for detained analysis based on PSpice and Cadence IC6 simulations with recently reported CMOS model of the ZC-CG-VDCC [36] and tested in range of pole frequency $\left(f_{\mathrm{p}}\right) 0.28$ $0.99 \mathrm{MHz}$ with quality factor $Q_{\mathrm{p}}$ equal to 2.58 . Lower quality factor $Q_{\mathrm{p}}=1$ (equality $R_{\mathrm{x}}=g_{\mathrm{m}}$ ) allows wider range of $f_{\mathrm{p}}$ control (between $0.24-2.7 \mathrm{MHz}$ ) than single parameter control (constant bandwidth). Theoretical presumptions were confirmed by detailed analysis and simulation. 


\section{Acknowledgments}

Manuscript received April 25, 2015; accepted July XX, 20XX. Research described in this paper was financed by Czech Ministry of Education in frame of National Sustainability Program under grant LO1401. For research, infrastructure of the SIX Center was used.

\section{References}

1. J. Baker, CMOS Circuit Design, Layout and Simulation, (Wiley-IEEE Press, West Sussex, 2005).

2. W. Tangsrirat, D. Prasertsom, Electronically tunable low-component-count current-mode biquadratic filter using dual-output current followers, Electrical Engineering Springer 90 (2007) 33-37.

3. A. U. Keskin, Multi-function biquad using single CDBA, Electrical Engineering Springer $\mathbf{8 8}$ (2006) 353-356.

4. D. Biolek, R. Senani, V. Biolkova, Z. Kolka, Active elements for analog signal processing: Classification, Review and New Proposals, Radioengineering 17 (2008) 15-32.

5. W. J. Kerwin, L. P. Huelsman, W. R. Newcomb, State variable synthesis for insensitive integrated circuit transfer functions, IEEE Journal of Solid State Circuits 2 (1967) 87-92.

6. R. L. Geiger, E. Sanchez-Sinencio, Active filter design using operational transconductance amplifiers: a tutorial, IEEE Circuits and Devices Magazine 1 (1985) 20-32.

7. M. T. Abuelmaatti, A. A. Bentrcia, A novel mixed-mode OTA-C universal filter, International Journal of Electronics 92 (2005) 375-383.

8. T. Tsukutani, Y. Sumi, Y. Kukui, Electronically tunable current-mode OTA-C biquad using two-integrator loop structure, Frequenz 60 (2006) 53-56.

9. H. Chen, Y. Liao, W. Lee, Tunable mixed-mode OTA-C universal filter, Analog Integrated Circuits and Signal Processing 58 (2008) 135-141.

10. H. A. Alzaher, M. Ismail, Current-mode universal filter using unity gain cells, Electronics Letters 35 (1999) 2198-2200.

11. R. Senani, S. S. Gupta, New universal filter using only current followers as active elements, International Journal of Electronics and Communication 60 (2006) 251-256.

12. G. Souliotis, C. Psychalinos, Current-Mode Linear Transformation Filters Using Current Mirrors, IEEE Transaction on Circuits and Systems II: Express Briefs 55 (2008) 541-545.

13. C. WANG, Y. Zhao, Q. Zhang, S. Du, A New Current Mode SIMO-Type Universal Biquad Employing Multi-Output Current Conveyors (MOCCIIs), Radioengineering 18 (2009) 83-88.

14. T. Tsukutani, Y. Sumi, Y. Fukui, Novel current-mode biquad filter using OTAs and DO-CCII, International Journal of Electronics 94 (2007) 99-105.

15. A. Sedra, K. C. Smith, A second generation current conveyor and its applications, IEEE Transaction on Circuit Theory 17 (1970) 132-134.

16. A. Fabre, O. Saaid, F. Wiest, C. Boucheron, High frequency applications based on a new current controlled conveyor, IEEE Trans. on Circuits and Systems - I 43 (1996) 82-91.

17. I. Eldbib, V. Musil, Self-cascoded current controlled CCII based tunable band pass filter, Proc. 18th Int. Conf. Radioelektronika (2008) doi: 10.1109/RADIOELEK.2008.4542706.

18. A. U. Keskin, D. Biolek, E. Hancioglu, V. Biolkova, Current-mode KHN filter employing Current Differencing Transconductance Amplifiers, International Journal of Electronics and Communications 60 (2006) 443-446.

19. A. Lahiri, A. A. Chowdhury, A novel First-Order Current-Mode All-Pass Filter Using CDTA, Radioengineering 18 (2009) 300-305. 
20. R. Prokop, V. Musil, Modular approach to design of modern circuit blocks for current signal processing and new device CCTA, Proc. Conference on Signal and Image Processing IASTED ( Anaheim, 2005) pp. 494-499.

21. M. Siripruchyanun, W. Jaikla, Current controlled current conveyor transconductance amplifier (CCCCTA): a building block for analog signal processing, Electrical Engineering Springer $\mathbf{9 0}$ (2008) 443-453.

22. N. Herencsar, J. Koton, K. Vrba, Electronically Tunable Phase Shifter Employing CurrentControlled Current Follower Transconductance Amplifiers (CCCFTAs), Proc. of the 32nd International Conference on Telecommunications and Signal Processing (Hungary, Dunakiliti, 2009) pp. 54-57.

23. A. Malcher, Modified current differencing transconductance amplifier - new versatile active element, Bulletin of the Polish Academy of Sciences: Technical Sciences 60 (2013) 739-750.

24. W. Surakampontorn, W. Thitimajshima, Integrable electronically tunable current conveyors, IEE Proceedings-G 135 (1988) 71-77.

25. A. Fabre, N. Mimeche, Class $\mathrm{A} / \mathrm{AB}$ second-generation current conveyor with controlled current gain, Electronics Letters 30 (1994) 1267-1268.

26. S. Minaei, O. K. Sayin, H. Kuntman, A new CMOS electronically tunable current conveyor and its application to current-mode filters, IEEE Trans. on Circuits and Systems - I 53 (2006) $1448-1457$.

27. M. Kumngern, S. Junnapiya, A sinusoidal oscillator using translinear current conveyors, Proc. Asia Pacific Conf. on Circuits and Systems APPCAS (Kuala Lumpur, 2010) pp. 740-743.

28. A. Marcellis, G. Ferri, N. C. Guerrini, G. Scotti, V. Stornelli, A. Trifiletti, The VGC-CCII: a novel building block and its application to capacitance multiplication, Analog Integrated Circuits and Signal Processing $\mathbf{5 8}$ (2009) 55-59.

29. R. Sotner, Z. Hrubos, N. Herensar, J. Jerabek, T. Dostal, Precise electronically adjustable oscillator suitable for quadrature signal generation employing active elements with current and voltage gain control, Circuits Systems and Signal Processing 33 (2014) 1-35.

30. A. Yesil, F. Kacar, Electronically tunable resistor-less mixed mode biquad filters, Radioengineering 22 (2013) 1116-1125.

31. J. Satansup, T. Pukkalanun, W. Tangsrirat, Electronically tunable single-input five-output voltage-mode universal filter using VDTAs and grounded passive elements, Circuits Systems and Signal Processing 32 (2013) 945-957.

32. M. Sagbas, M. Koksal, Realization of a general resistorless active biquad using CBTA, Journal of Circuits, Systems amd Computer 21 (2012) 125-136.

33. B. Chatuverdi, S. Maheshwari, Current-mode biquad filter with minimum component count, Active and Passive Electronic Components 2011 (2011) 1-8.

34. S. V. Singh, R. S. Tomar, D. S. Chauhan, Single CCTA-based four input single output voltage-mode universal biquad filter, International Journal of Computer Science and Information Security 11 (2013) 115-119.

35. R. Sotner, J. Jerabek, B. Sevcik, Novel solution of notch/all-pass filter with special electronic adjusting of attenuation in the stop band, Elektronika IR Elektrotechnika 113 (2011) 37-42.

36. R. Sotner, N. Herencsar, J. Jerabek, R. Prokop, T. Dostal, K. Vrba, Z-Copy controlled-gain voltage differencing current conveyor: Advanced possibilities in direct electronic control of 1st-order filter, Elektronika IR Elektrotechnika 20 (2014) 77-83.

37. R. Sotner, N. Herencsar, J. Jerabek, K. Vrba, T. Dostal, V. Jaikla, B. Metin, Novel first-order all-pass filter applications of z- copy voltage differencing current conveyor, Indian Journal of Pure and Applied Physics, 53 (2015) 537-545.

38. R. Sotner, J. Jerabek, J. Petrzela, K. Vrba, T. Dostal, Design of Fully Adjustable Solution of Band-Reject/All- Pass Filter Transfer Function Using Signal Flow Graph Approach, Proc. of the 24th International Conference Radioelektronika (Bratislava, Slovakia, 2014) pp. 67-70. 
20 Jan Jerabek, Roman Sotner, Josef Polak, Lukas Langhammer, Norbert Herencsar et al.

39. R. Sotner, J. Petrzela, J. Jerabek, K. Vrba, T. Dostal, Solutions of Reconnection-less OTAbased Biquads with Electronical Transfer Response Reconfiguration, Proc. of 25th International Conference Radioelektronika (Pardubice, Czech republic, 2015) pp. 40-45.

40. R. Sotner, J. Petrzela, J. Jerabek, T. Dostal, Reconnection-less OTA- based Biquad Filter with Electronically Reconfigurable Transfers, Elektronika Ir Elektrotechnika, 21 (2015) 33-37.

41. Ch-N. Lee, Ch-M. Chang, Single FDCCII-based mixed-mode biquad filter with eight outputs, AEU - Int. Journal of Electronics and Communications, 63 (2009) 736-742.

42. F. Kacar, A. Yesil, H. Kuntman, Current-Mode Biquad Filters Employing Single FDCCII, Radioengineering, 21 (2012) 1269-1278.

43. R. K. Sharma, R. Senani, Universal current mode biquad using a single CFOA, Int. Journal of Electronics, 91 (2004) 175-183.

44. M. Sagbas, U. E. Ayten, H. Sedef, Current and voltage transfer function filters using a single active device, IET Circuits , Devices and Systems, 4 (2010) 78-86. 